\title{
Effects of Dietary Unsaturated Fatty Acid and Chronic Carbon Tetrachloride Treatment on the Accumulation of Oxidation Products, $\alpha$-Tocopherol and Liver Injury in Mice
}

\author{
Satoshi Yasuda, ${ }^{a}$ Shiro Watanabe, ${ }^{*}, a$ Tetsuyuki Kobayashi, ${ }^{b}$ and Harumi OKuyama ${ }^{a}$ \\ Department of Biological Chemistry, Faculty of Pharmaceutical Sciences, Nagoya City University, ${ }^{a}$ 3-1 Tanabedori, \\ Mizuhoku, Nagoya 467-8603, Japan and Department of Biology, Faculty of Science, Ochanomizu University, ${ }^{b} 2-1-1$ \\ Otsuka, Bunkyo-ku, Tokyo 112-8610, Japan. Received April 10, 1998; accepted July 3, 1998
}

\begin{abstract}
Mice, at weaning, were placed on a diet supplemented with beef tallow (BT), linoleic acid (18:2n-6)-rich safflower oil (SO), $\alpha$-linolenic acid (18:3n-3)-rich perilla oil (PO) or docosahexaenoic acid (22: 6n-3, DHA)-rich fish oil (FO) to modify membrane fatty acid vulnerability to peroxidation, then carbon tetrachloride $\left(\mathrm{CCl}_{4}\right)$ was administered chronically. $\mathrm{CCl}_{4}$-induced liver injury, estimated using serum alanine aminotransferase activity and liver hydroxyproline content, was not different among the 4 dietary groups; however, the FO diet lowered the liver triacylglycerol (TG) level when compared with the BT and SO diets. The FO diet group exhibited a significantly higher level of thiobarbituric acid-reactive substances (TBARS) in the liver when compared with the three other dietary groups. Chronic $\mathrm{CCl}_{4}$ treatment decreased the proportion of eicosanoid precursors (arachidonate and eicosapentaenoate) rather than that of DHA, with the highest peroxidizability among major fatty acids in liver, and did not enhance TBARS formation in any of the dietary groups. The protein carbonyl content in the liver was similar among the 4 dietary groups but was decreased following $\mathbf{C C l}_{4}$ treatment. Liver $\alpha$-tocopherol contents were affected both by diet and $\mathrm{CCl}_{4}$ treatment, and a positive correlation was observed between $\alpha$-tocopherol and TG contents. These results indicate that increasing the autoxidizability of dietary fatty acids or the chronic $\mathrm{CCl}_{4}$ treatment did not synergistically enhance liver injury or the accumulation of oxidation products in mice.
\end{abstract}

Key words carbon tetrachloride; dietary fatty acid; lipid peroxidation; liver injury

Carbon tetrachloride $\left(\mathrm{CCl}_{4}\right)$ has been used extensively to induce liver injury in experimental animals. $\mathrm{CCl}_{4}$, incorporated into liver cells, is metabolized by microsomal cytochrome $\mathrm{P}-450$ to the trichloromethyl radical $\left(\mathrm{CCl}_{3} \cdot\right)$ which is assumed to initiate free radical-mediated lipid peroxidation leading to the accumulation of lipid-derived oxidation products which cause liver injury. ${ }^{1,2)}$ The conclusions from animal models have often been extended to support the free radical theory for aging, carcinogenesis and atherosclerosis that long-term feeding of easily autoxidizable fatty acids results in the accumulation of lipid peroxides which enhance free radical injury. ${ }^{3-7)}$ In fact, the enhanced accumulation of peroxidation products, estimated mainly as thiobarbituric acidreactive substances (TBARS), has been reported in both human and experimental animals supplemented with fish oil. ${ }^{8,9)}$ Moreover, several studies have reported decreased tocopherol contents in tissues following feeding with fish oil, which is recognized as a consequence of the augmented requirement for endogenous antioxidants, presumably due to enhanced lipid peroxidation in the body. ${ }^{10-12)}$

However, dietary fish oil enriched with eicosapentaenoic acid (20:5n-3, EPA) and/or docosahexaenoic acid (22:6n-3, DHA) as well as perilla oil enriched with $\alpha$-linolenic acid $(18: 3 n-3)$ has been proven to suppress cardiovascular and inflammatory diseases as well as carcinogenesis. ${ }^{13,14)}$ Lowering the availability of arachidonic acid (20:4n-6, AA) for eicosanoid synthesis is considered to form the major biochemical basis for the beneficial effects of these n-3 fatty acids.

Previously, we have reported that dietary supplementation with DHA-rich fish oil resulted in a marked accumulation of DHA in serum and liver lipids, but liver injury following a single injection of $\mathrm{CCl}_{4}$ was not accelerated when compared

* To whom correspondence should be addressed. with results following a beef tallow diet enriched with saturated and monoenoic fatty acids. ${ }^{15)}$ In addition, the fish oil diet and $\mathrm{CCl}_{4}$ injection resulted in no synergistic accumulation of lipid peroxide products, estimated as thiobarbituric acid-reactive substances (TBARS) or conjugated dienes. These results are apparently inconsistent with the autoxidation-related lipid peroxide theory of so-called free radical diseases. However, it remains to be defined whether chronic $\mathrm{CCl}_{4}$ treatment causes more extensive peroxidative damage of membrane lipids and accelerates liver injury in animals fed a fish oil diet as compared with those fed diets containing less autoxidizable fatty acids.

In the present study, we evaluated the effect of dietary fatty acids with varying autoxidizability on liver injury, the accumulation of oxidation products (TBARS and protein carbonyl), tocopherol content and fatty acid composition in mice chronically treated with $\mathrm{CCl}_{4}$.

\section{MATERIALS AND METHODS}

Dietary Protocols and Animal Treatment Female ICR mice at 3 weeks of age (Shizuoka Laboratory Animals Co., Ltd., Shizuoka, Japan) were divided randomly into 4 groups and were fed a diet supplemented either with beef tallow (BT) (Wako Pure Chemical Co., Osaka, Japan), safflower seed oil (SO), perilla seed oil (PO) (Ohta Oil Co., Ltd., Okazaki, Aichi, Japan), or with DHA-rich fish oil (FO) (Harima Chemicals Inc., Tokyo) for 10 weeks. The test diets were prepared by mixing a conventional diet (CE-2, Clea Japan, Inc., Tokyo) with $10 \%$ oils; the final lipid content in the diets was determined to be $12.7 \%$ corresponding to 29.7 en. $\%$. The fatty acid compositions of the diets are shown in Table 1 . The peroxidizability index was calculated by the fol-

(C) 1998 Pharmaceutical Society of Japan 
Table 1. Fatty Acid Composition of Experimental Diets

\begin{tabular}{lcccr}
\hline \hline & \multicolumn{4}{c}{$\%$ of Total fatty acids ${ }^{a}$} \\
\cline { 2 - 5 } Fatty acid & BT diet & SO diet & PO diet & FO diet \\
\hline $14: 0$ & 2.0 & 0.1 & 0.2 & 2.0 \\
$16: 0$ & 23.5 & 8.9 & 8.6 & 14.7 \\
$16: 1$ & 2.2 & 0.3 & 0.3 & 4.5 \\
$18: 0$ & 13.6 & 2.2 & 1.7 & 2.5 \\
$18: 1 \mathrm{n}-9^{b)}$ & 39.3 & 15.5 & 16.5 & 16.2 \\
$18: 2 \mathrm{n}-6$ & 15.8 & 69.0 & 23.7 & 16.7 \\
$18: 3 \mathrm{n}-3$ & 1.2 & 1.5 & 47.0 & 1.8 \\
$20: 1$ & 0.6 & 0.5 & 0.5 & 1.3 \\
$20: 4 \mathrm{n}-6$ & 0.1 & 0.1 & 0.1 & 1.7 \\
$20: 5 \mathrm{n}-3$ & 0.6 & 0.7 & 0.6 & 7.0 \\
$22: 5 \mathrm{n}-6$ & $\mathrm{~N} . \mathrm{D}$. & N.D. & N.D. & 1.6 \\
$22: 6 \mathrm{n}-3$ & 0.6 & 0.7 & 0.6 & 29.5 \\
& & & & \\
$\mathrm{n}-6 / \mathrm{n}-3^{c)}$ & 6.43 & 24.20 & 0.50 & 0.53 \\
Peroxidizability index ${ }^{d)}$ & 30.0 & 83.1 & 128.1 & 316.5 \\
\hline
\end{tabular}

The test diets were prepared by mixing a conventional diet containing $3 \%$ lipids and beef tallow, safflower oil, perilla oil or fish oil at a $9: 1$ weight ratio, and the final lipid content was $12.7 \%$ a) The fatty acid composition was analyzed using gas liquid chromatography. $b$ ) The position of the double bond numbered from the methyl terminus is designated as $n-9, n-6$ or $n-3$. c) $n-6 / n-3$ indicates the total $n-6$ fatty acids/ total n-3 fatty acids ratio. $d)$ Peroxidizability Index $=(\%$ of monoenoate $\times 0.025)+(\%$ of dienoate $\times 1)+(\%$ of trienoate $\times 2)+(\%$ of tetraenoate $\times 4)+(\%$ of pentaenoate $\times 6)+$ $(\%$ of hexaenoate $\times 8){ }^{16)}$ N.D., not detected.

lowing equation: $\%$ of monoenoate $\times 0.025+\%$ of dienoate $\times$ $1+\%$ of trienoate $\times 2+\%$ of tetraenoate $\times 4+\%$ of pentaenoate $\times 6+\%$ of hexaenoate $\times 8{ }^{16)}$ The concentration of $\alpha$ tocopherol in the test diets was adjusted to $250 \mathrm{mg} / \mathrm{kg}$ of diet by adding $\alpha$-tocopherol (Sigma, St. Louis, MO, U.S.A.). The test diets were kept frozen at $-20{ }^{\circ} \mathrm{C}$ for less than 2 weeks until serving. Diets were replaced every other day to keep the peroxide values of ingested diets below $30 \mathrm{meq} / \mathrm{kg}$ of oil. Mice were kept at $23 \pm 2{ }^{\circ} \mathrm{C}$ and fed ad libitum. Experimental mice received subcutaneously $1 \mathrm{ml}$ of $\mathrm{CCl}_{4} / \mathrm{kg}$ body weight, which was dissolved in olive oil; control animals received olive oil twice a week from the third week to the tenth week of the feeding. All mice were sacrificed $3 \mathrm{~d}$ following the last injection to obtain sera and livers. The livers were frozen quickly in liquid nitrogen. Sera and livers were stored at $-20^{\circ} \mathrm{C}$ and $-80^{\circ} \mathrm{C}$, respectively, until analysis.

Determination of Serum Alanine Aminotransferase Activity Serum alanine aminotransferase (ALT) activity was measured spectrophotometrically. In brief, serum samples were incubated at $30^{\circ} \mathrm{C}$ in $100 \mathrm{~mm}$ Tris-HCl buffer $(\mathrm{pH}$ 7.3) containing $500 \mathrm{~mm}$ L-alanine, $12 \mathrm{~mm}$ 2-oxoglutarate, $0.18 \mathrm{~mm}$ pyridoxal 5-phosphate, $0.18 \mathrm{~mm} \mathrm{NADH}$, and 1200 $\mathrm{U} / 1$ lactate dehydrogenase, and the absorbance at $340 \mathrm{~nm}$ was monitored. ${ }^{17)}$

Determination of Liver Hydroxyproline Content Liver hydroxyproline content was determined to evaluate the degree of liver fibrosis using the method reported by Woesser ${ }^{18)}$ with slight modifications. Liver homogenates were prepared in $6 \mathrm{~N} \mathrm{HCl}$, heated at $110^{\circ} \mathrm{C}$ for $18 \mathrm{~h}$ and then neutralized with $6 \mathrm{~N} \mathrm{NaOH}$. An aliquot of the hydrolysates was filtered through a filter paper and treated with $32 \mathrm{~mm}$ chloramine-T for $20 \mathrm{~min}$ at room temperature and then with $9 \%$ perchloric acid- $0.6 \mathrm{~mm} p$-dimethylaminobenzaldehyde for $15 \mathrm{~min}$ at $60{ }^{\circ} \mathrm{C}$. The absorbance at $557 \mathrm{~nm}$ of the reaction mixture was converted into a hydroxyproline concentration using a calibration curve of standards based on the L-hydroxyproline
(Wako)

Determination of Liver TBARS Liver was homogenized in cold $1.15 \% \mathrm{KCl}$ to prepare $10 \%(\mathrm{w} / \mathrm{v})$ homogenates. The TBARS in the liver homogenates was measured according to a method described by Kikugawa et al. ${ }^{19}$; butylated hydroxytoluene (BHT) was added to the coloring reaction mixture at $0.02 \%$ to prevent peroxidation during the assay. A calibration curve for the quantitation of liver TBARS content was established using standards of malonaldehyde-bis(dimethylacetal) (Aldrich, Milwaukee, WI, U.S.A.).

Determination of Protein Carbonyl Contents Liver homogenates $(10 \%, \mathrm{w} / \mathrm{v})$ were prepared in cold phosphatebuffered saline supplemented with leupeptin $(5 \mu \mathrm{g} / \mathrm{ml})$ and phenylmethylsulfonyl fluoride $(40 \mu \mathrm{g} / \mathrm{ml})$. The supernatant, obtained using centrifugation at $6000 \times \boldsymbol{g}$ for $10 \mathrm{~min}$, was divided into two aliquots, and protein was precipitated with $10 \%$ trichloroacetic acid (TCA). Protein carbonyl content was measured using the method reported by Nakamura and Goto. ${ }^{20)}$ Each protein pellet was dissolved either in $10 \mathrm{~mm}$ 2,4-dinitrophenylhydrazine (DNPH) in $2 \mathrm{~N} \mathrm{HCl}$ or in $2 \mathrm{~N} \mathrm{HCl}$. The mixtures were allowed to stand at room temperature for $1 \mathrm{~h}$ with gentle mixing every $10 \mathrm{~min}$. Protein pellets were reformed by treating the mixtures with $10 \%$ TCA; the mixture were then washed three times with ethanol-ethyl acetate $(1: 1, \mathrm{v} / \mathrm{v})$ and dissolved in $8 \mathrm{M}$ urea. The absorbance at 360 $\mathrm{nm}$ was measured and the carbonyl content was expressed as nmol of dinitrophenyl group per mg of protein using an extinction coefficient at $22.0 \mathrm{~mm}^{-1} \mathrm{~cm}^{-1}$. Protein concentration was determined using a commercial protein assay kit (BioRad, Richmond, CA).

Determination of $\boldsymbol{\alpha}$-Tocopherol $\alpha$-Tocopherol was extracted from the liver and diets using chloroform/methanol. ${ }^{21)}$ The extracts from the diets were saponified with $1 \mathrm{~N}$ ethanolic $\mathrm{KOH}$ in the presence of $5.5 \%(\mathrm{w} / \mathrm{v})$ pyrogallol, and $\alpha$-tocopherol was extracted with $n$-hexane. The $\alpha$-tocopherol was measured using normal phase high-performance liquid chromatography (HPLC) ${ }^{22)}$ on a LiChrosorb $5 \mathrm{NH}_{2}$ column $(4.6 \times$ $150 \mathrm{~mm}$ ) (GL Sciences Inc., Tokyo) equilibrated with $n$ hexane-isopropanol $(98: 2, \mathrm{v} / \mathrm{v})$ at $40^{\circ} \mathrm{C}$; the elution rate was $0.8 \mathrm{ml} / \mathrm{min}$. $\alpha$-Tocopherol was monitored fluorometrically (excitation at $298 \mathrm{~nm}$ and emission at $325 \mathrm{~nm}$ ). 2,2,5,7,8-Pentamethyl-6-hydroxychroman (Wako) was added prior to the extraction steps as an internal standard.

Analysis of Liver Triacylglycerol and Phospholipids Total lipids were extracted from the liver according to the method reported by Bligh and Dyer. ${ }^{21)}$ Triacylglycerol (TG) and phospholipid classes were separated using thin-layer chromatography (TLC) on a Silica Gel G plate (E. Merck, Darmstadt, Germany) using petroleum ether-diethyl etheracetic acid ( $80: 30: 1$, by vol.) and chloroform-methanolacetic acid-formic acid-water (35:15:6:2:1, by vol.), respectively, as developing solvents. The TG and phospholipids separated on TLC plates were visualized under ultraviolet light after spraying with primuline (Nacalai Tesque Co., Kyoto, Japan), and were extracted from the adsorbents according to the method reported by Bligh and Dyer. ${ }^{21)}$ Fatty acids in the TG and phospholipid classes were converted to methyl esters by treatment with $5 \%(\mathrm{w} / \mathrm{v}) \mathrm{HCl}$ in methanol for $1 \mathrm{~h}$ in a boiling water bath and then quantitated by gas-liquid chromatography using a capillary column (DB225, J\&W Scientific, Folsom, CA). Triheptadecanoylglyc- 

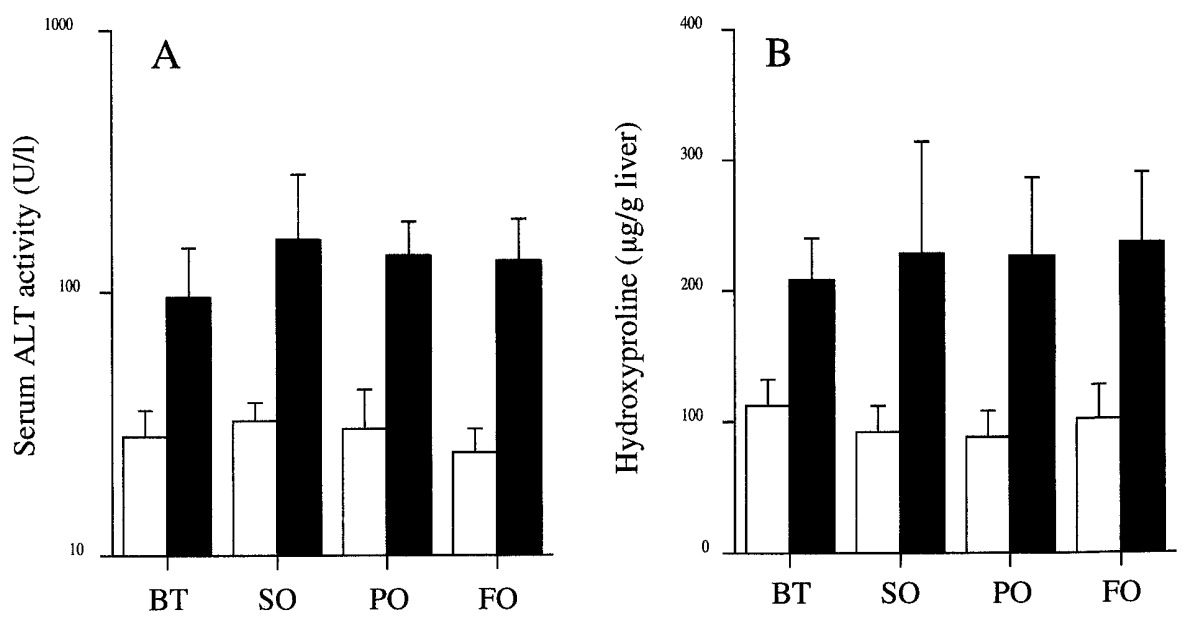

Fig. 1. Serum ALT Activity (A) and Liver Hydroxyproline Content (B) in Mice Fed the BT, SO, PO or FO Diets for 10 Weeks and Treated with Vehicle (Open Bar) or $\mathrm{CCl}_{4}$ (Solid Bar) Twice a Week from the Third Week to the Tenth Week

In the two way ANOVA, an effect of $\mathrm{CCl}_{4}$ treatment $(p<0.01)$ but not of diet on serum ALT activities $(\mathrm{A})$ and liver hydroxyproline content $(\mathrm{B})$ was observed. Each column with a bar represents the mean \pm S.D. $\left(n=3-4\right.$ in vehicle-treated mice; $n=10-13$ in $\mathrm{CCl}_{4}$-treated mice $)$.

erol (Sigma), 1,2-diheptadecanoyl-L- $\alpha$-phosphatidylcholine (Sigma) and 1,2-diheptadecanoyl-L- $\alpha$-phosphatidylethanolamine (Sigma) were used as internal standards.

Statistical Analysis Data are presented as means \pm S.D. The significance of the effects of diet, $\mathrm{CCl}_{4}$ treatment and their interaction were analyzed by a two-way analysis of variance (ANOVA), and the significance of mean differences among the dietary groups was examined by means comparisons using commercially available software (Super ANOVA v1.11, Abacus Concepts, Inc., Berkeley, CA). A probability below 0.05 was considered significant.

\section{RESULTS}

Liver Injury Serum ALT activity as a measure of liver injury was elevated in $\mathrm{CCl}_{4}$-treated groups as compared with vehicle-treated control groups $(p<0.01)$ (Fig. 1A). However, no significant difference in serum ALT activity was observed among the 4 dietary groups. It is known that the chronic administration of $\mathrm{CCl}_{4}$ to experimental animals induces liver fibrosis in which the extensive accumulation of intracellular matrix constituents such as collagen and laminin occurs. ${ }^{23)}$ Liver hydroxyproline content, determined as total collagen content, was significantly increased in all the $\mathrm{CCl}_{4}$-treated groups as compared with the control groups $(p<0.01)$ (Fig. $1 \mathrm{~B})$. However, there was no significant difference in the elevated hydroxyproline contents in the livers among the 4 dietary groups.

Thiobarbituric Acid-Reactive Substances Contents in Liver Generally, TBARS have been determined as a measure of aldehydes derived from the peroxidative degradation of PUFA. ${ }^{19)}$ Liver TBARS content measured in the presence of BHT in assay mixtures was significantly higher in the FO diet group as compared with other groups in both the vehicle and $\mathrm{CCl}_{4}$-treated groups $(p<0.01)$ (Fig. 2), although there was no significant effect of $\mathrm{CCl}_{4}$ treatment on liver TBARS content in any of the dietary groups.

Liver Protein Carbonyl Contents in Liver Protein carbonyls are assumed to be formed through the covalent modification of proteins by oxidatively decomposed PUFA. ${ }^{24)}$

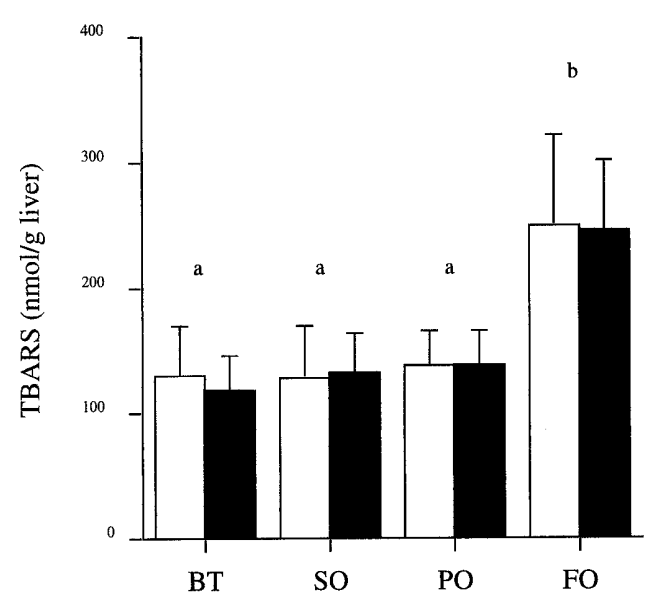

Fig. 2. Liver TBARS Content in Mice Fed the BT, SO, PO or FO Diets for 10 Weeks and Treated with Vehicle (Open Bar) or $\mathrm{CCl}_{4}$ (Solid Bar) Twice a Week from the Third Week to the Tenth Week

In the two way ANOVA, an effect of diet $(p<0.01)$ but not $\mathrm{CCl}_{4}$ treatment was observed. Values with different letters are significantly different $(p<0.05)$ by means comparisons among the dietary groups. Each column with a bar represents the mean \pm S.D. $(n=8)$.

However, the protein carbonyl content in liver was significantly reduced in all the $\mathrm{CCl}_{4}$-treated groups compared with the vehicle-treated groups $(p<0.05)$. Furthermore, the protein carbonyl content in liver did not differ among the 4 dietary groups (Fig. 3).

$\alpha$-Tocopherol Contents in Liver The $\alpha$-tocopherol content in the liver in the BT diet group was higher than that in the other dietary groups, in both the vehicle- and the $\mathrm{CCl}_{4}$ treated groups $(p<0.01)$ (Fig. 4). However, $\mathrm{CCl}_{4}$ treatment significantly increased liver $\alpha$-tocopherol content $(p<0.01)$, and the $\alpha$-tocopherol content was increased significantly synergistically by diet and $\mathrm{CCl}_{4}$ treatment $(p<0.01)$.

Triacylglycerol and Phospholipid Classes in Liver Fatty acid compositions of diets were reflected by the TG content in liver (Table 2). $\mathrm{CCl}_{4}$ treatment significantly increased oleate $(18: 1)(p<0.01)$ and decreased palmitate $(16: 0)(p<$ $0.01)$ compared with the vehicle treatment. Liver TG content was elevated significantly by $\mathrm{CCl}_{4}$ treatment $(p<0.01)$, and 
was higher in the BT and SO diet groups than in the FO diet group $(p<0.05)$.

In the SO diet group, AA in phosphatidylcholine (PC) $(p<0.01)$ and phosphatidylethanolamine (PE) $(p<0.01)$ was significantly higher than in the other dietary groups (Tables 3 and 4). Feeding with the PO diet increased EPA $(p<0.01)$ and decreased AA $(p<0.01)$ as compared with the BT and SO diet groups. The FO diet markedly increased DHA content in PC $(p<0.01)$ and PE $(p<0.01)$, although this diet did not decrease AA as much as the PO diet. Associated with these changes induced by the FO diet, the autoxidizability of fatty acids, calculated as the peroxidizability index, was significantly higher than in other three dietary groups $(p<0.01)$.

PC, the most abundant phospholipid, was decreased in liver from the $\mathrm{CCl}_{4}$-treated mice compared with untreated

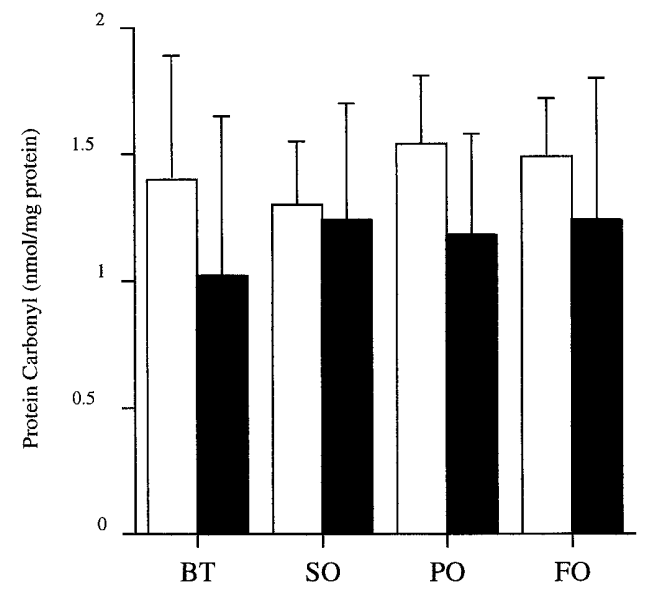

Fig. 3. Liver Protein Carbonyl Content in Mice Fed the BT, SO, PO or FO Diets for 10 Weeks and Treated with Vehicle (Open Bar) or $\mathrm{CCl}_{4}$ (Solid Bar) Twice a Week from the Third Week to the Tenth Week

In the two way ANOVA, an effect of $\mathrm{CCl}_{4}$ treatment $(p<0.05)$ but not of diet was observed. Each column with a bar represents the mean \pm S.D. $(n=6)$. mice $(p<0.05)$, although the PC content was similar among the 4 dietary groups. The PE content was not changed by chronic $\mathrm{CCl}_{4}$ treatment. An increase in palmitate (16:0) $(p<0.01)$ and a decrease in stearate $(18: 0)(p<0.05)$ by $\mathrm{CCl}_{4}$ treatment were observed only in $\mathrm{PC}$ of the liver. The proportions of both DHA $(p<0.01)$ and AA $(p<0.01)$ in PC were decreased significantly in the $\mathrm{CCl}_{4}$-treated groups as compared with the untreated groups. The PE contained more DHA than other phospholipid classes in liver, and the proportions of $\mathrm{AA}$ in $\mathrm{PE}$ were also decreased by $\mathrm{CCl}_{4}$ treatment $(p<0.01)$; however a significant increase in the proportions of DHA was observed in the $\mathrm{CCl}_{4}$-treated groups compared with the vehicle-treated groups $(p<0.01)$.

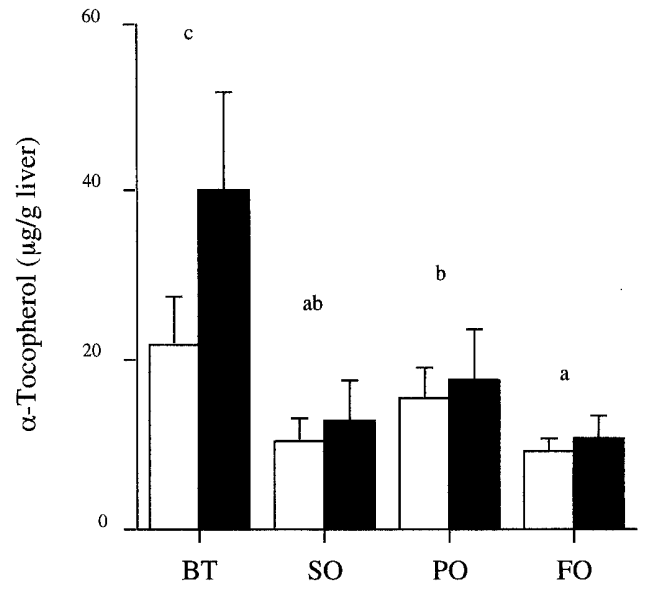

Fig. 4. Liver $\alpha$-Tocopherol Contents in Mice Fed the BT, SO, PO or FO Diets for 10 Weeks and Treated with Vehicle (Open Bar) or $\mathrm{CCl}_{4}$ (Solid Bar) Twice a Week from the Third Week to the Tenth Week

In the two way ANOVA, there were effects of diet $(p<0.01)$ and $\mathrm{CCl}_{4}$ treatment $(p<0.01)$, and the interaction between diet and $\mathrm{CCl}_{4}$ treatment $(p<0.01)$ was observed. Values with different letters are significantly different $(p<0.05)$ by means comparisons among the dietary groups. Each column with a bar represents the mean \pm S.D. $(n=5-$

Table 2. Fatty Acid Composition of Liver TG in Mice Fed the Experimental Diets

\begin{tabular}{|c|c|c|c|c|c|c|c|c|c|c|c|c|}
\hline \multirow{3}{*}{ Fatty acid } & \multicolumn{12}{|c|}{$\%$ of Total fatty acid } \\
\hline & \multicolumn{2}{|c|}{$\mathrm{BT}$} & \multicolumn{2}{|c|}{ SO } & \multicolumn{2}{|c|}{ PO } & \multicolumn{2}{|c|}{$\mathrm{FO}$} & \multirow{2}{*}{$\begin{array}{l}\text { Pooled } \\
\text { S.D. }\end{array}$} & \multicolumn{3}{|c|}{ ANOVA } \\
\hline & Control & $\mathrm{CCl}_{4}$ & Control & $\mathrm{CCl}_{4}$ & Control & $\mathrm{CCl}_{4}$ & Control & $\mathrm{CCl}_{4}$ & & Diet & $\mathrm{CCl}_{4}$ & $\operatorname{Diet} \times \mathrm{CCl}_{4}$ \\
\hline $14: 0$ & 0.5 & $0.4 \mathrm{~b}$ & 0.4 & $0.2 \mathrm{a}$ & 0.4 & $0.5 \mathrm{ab}$ & 0.7 & $0.5 \mathrm{c}$ & 0.2 & $<0.01$ & NS & NS \\
\hline $16: 0$ & 23.6 & $16.5 \mathrm{~b}$ & 17.4 & $13.6 \mathrm{a}$ & 17.5 & $13.8 \mathrm{a}$ & 21.3 & $17.3 \mathrm{~b}$ & 2.9 & $<0.01$ & $<0.01$ & NS \\
\hline $16: 1$ & 2.5 & $2.2 \mathrm{~b}$ & 1.9 & $1.6 \mathrm{a}$ & 2.1 & $2.5 \mathrm{ab}$ & 3.4 & $2.9 \mathrm{c}$ & 0.8 & $<0.01$ & NS & NS \\
\hline $18: 0$ & 3.1 & $2.8 \mathrm{a}$ & 2.1 & $2.4 \mathrm{a}$ & 3.1 & $3.2 \mathrm{a}$ & 6.2 & $3.5 \mathrm{~b}$ & 1.2 & $<0.01$ & NS & $<0.05$ \\
\hline $18: 1$ & 51.9 & $57.3 \mathrm{c}$ & 19.9 & $21.5 \mathrm{a}$ & 27.0 & $28.8 \mathrm{~b}$ & 23.3 & $30.3 \mathrm{~b}$ & 3.7 & $<0.01$ & $<0.01$ & NS \\
\hline $18: 2 n-6$ & 14.0 & $14.2 \mathrm{a}$ & 53.3 & $53.7 \mathrm{c}$ & 25.3 & $21.6 \mathrm{~b}$ & 17.0 & $15.1 \mathrm{a}$ & 3.1 & $<0.01$ & NS & NS \\
\hline $18: 3 n-3$ & 0.4 & $0.5 \mathrm{a}$ & 0.5 & $0.5 \mathrm{a}$ & 19.6 & $21.5 \mathrm{~b}$ & 1.1 & $0.8 \mathrm{a}$ & 1.0 & $<0.01$ & NS & NS \\
\hline $20: 1$ & 0.9 & 2.4 & 0.4 & 0.4 & 0.3 & 0.5 & 0.3 & 2.1 & 1.2 & NS & $<0.05$ & NS \\
\hline $20: 3 n-6$ & 0.3 & $0.6 \mathrm{a}$ & 1.1 & $1.9 \mathrm{~b}$ & 0.3 & $0.6 \mathrm{a}$ & 0.2 & $0.3 \mathrm{a}$ & 0.4 & $<0.01$ & $<0.01$ & NS \\
\hline $20: 4 n-6$ & 0.6 & $0.6 \mathrm{a}$ & 1.6 & $1.7 \mathrm{c}$ & 0.5 & $0.4 \mathrm{a}$ & 1.4 & $1.1 \mathrm{~b}$ & 0.3 & $<0.01$ & NS & NS \\
\hline $20: 5 n-3$ & tr. & $0.2 \mathrm{a}$ & N.D. & tr. a & 1.4 & $1.5 \mathrm{~b}$ & 2.6 & $2.2 \mathrm{c}$ & 0.3 & $<0.01$ & NS & NS \\
\hline $22: 5 n-3$ & N.D. & N.D. a & N.D. & tr. a & 0.8 & $1.9 \mathrm{~b}$ & 2.0 & $2.0 \mathrm{c}$ & 0.6 & $<0.01$ & NS & NS \\
\hline $22: 6 n-3$ & 2.0 & $2.0 \mathrm{a}$ & 1.1 & $1.7 \mathrm{a}$ & 1.6 & $3.2 \mathrm{a}$ & 20.3 & $21.5 \mathrm{~b}$ & 3.2 & $<0.01$ & NS & NS \\
\hline PI & 37 & $40 \mathrm{a}$ & 74 & $90 \mathrm{~b}$ & 94 & $122 \mathrm{~b}$ & 218 & $239 \mathrm{c}$ & 31 & $<0.01$ & NS & NS \\
\hline $\begin{array}{l}\text { Total fatty acids } \\
\text { (mg/g liver) }\end{array}$ & 9.7 & $20.2 \mathrm{~b}$ & 10.4 & $14.4 \mathrm{~b}$ & 6.9 & $14.8 \mathrm{ab}$ & 3.5 & $8.8 \mathrm{a}$ & 6.3 & $<0.05$ & $<0.01$ & NS \\
\hline
\end{tabular}

Mice were fed the BT, SO, PO or FO diets for 10 weeks and treated with vehicle or $\mathrm{CCl}_{4}$ twice a week from the third week to the tenth week. Samples were taken $3 \mathrm{~d}$ following the last injection. Lipids were extracted from liver with chloroform-methanol, and TG was separated by thin-layer chromatography on a silica gel and quantified by gas-liquid chromatography. Values are means from 5 mice. Values with different letters are significantly different $(p<0.05)$ by means comparisons among the dietary groups. a) Pooled S.D. $=$ (Error sum of squares/degree of freedom) ${ }^{1 / 2}$. Abbreviations used are: N.D., not detected; NS, not significant; tr., trace; PI, Peroxidizability Index. 
Table 3. Fatty Acid Composition of Liver PC in Mice Fed the Experimental Diets

\begin{tabular}{|c|c|c|c|c|c|c|c|c|c|c|c|c|}
\hline \multirow{3}{*}{ Fatty acid } & \multicolumn{12}{|c|}{$\%$ of Total fatty acid } \\
\hline & \multicolumn{2}{|c|}{$\mathrm{BT}$} & \multicolumn{2}{|c|}{ SO } & \multicolumn{2}{|c|}{ PO } & \multicolumn{2}{|c|}{ FO } & \multirow{2}{*}{$\begin{array}{l}\text { Pooled } \\
\text { S.D. }^{a)}\end{array}$} & \multicolumn{3}{|c|}{ ANOVA } \\
\hline & Control & $\mathrm{CCl}_{4}$ & Control & $\mathrm{CCl}_{4}$ & Control & $\mathrm{CCl}_{4}$ & Control & $\mathrm{CCl}_{4}$ & & Diet & $\mathrm{CCl}_{4}$ & $\operatorname{Diet} \times \mathrm{CCl}_{4}$ \\
\hline $16: 0$ & 26.1 & $28.8 \mathrm{a}$ & 25.0 & $26.6 \mathrm{a}$ & 25.8 & $28.6 \mathrm{a}$ & 29.7 & $32.1 \mathrm{~b}$ & 2.0 & $<0.01$ & $<0.01$ & NS \\
\hline $16: 1$ & 0.8 & 1.1 & 0.5 & 0.9 & 0.6 & 0.9 & 0.6 & 1.4 & 0.4 & NS & $<0.01$ & NS \\
\hline $18: 0$ & 17.7 & $14.4 \mathrm{ab}$ & 18.7 & $18.7 \mathrm{c}$ & 18.6 & $17.1 \mathrm{bc}$ & 15.1 & $13.5 \mathrm{a}$ & 1.9 & $<0.01$ & $<0.05$ & NS \\
\hline $18: 1$ & 12.8 & $18.0 \mathrm{c}$ & 5.7 & $7.5 \mathrm{a}$ & 8.5 & $10.3 \mathrm{~b}$ & 6.8 & $11.1 \mathrm{~b}$ & 1.0 & $<0.01$ & $<0.01$ & $<0.01$ \\
\hline $18: 2 n-6$ & 17.3 & $14.6 \mathrm{~b}$ & 21.4 & $20.9 \mathrm{c}$ & 23.1 & $22.3 \mathrm{~d}$ & 10.0 & $9.9 \mathrm{a}$ & 1.4 & $<0.01$ & $<0.05$ & NS \\
\hline $18: 3 n-3$ & 0.2 & $0.4 \mathrm{a}$ & 0.2 & $0.4 \mathrm{a}$ & 1.9 & $1.3 \mathrm{~b}$ & 0.4 & $0.4 \mathrm{a}$ & 0.3 & $<0.01$ & NS & $<0.05$ \\
\hline $20: 0$ & 0.2 & 0.3 & 0.2 & 0.2 & 0.1 & 0.2 & 0.1 & 0.2 & 0.1 & NS & $<0.05$ & NS \\
\hline $20: 1$ & 0.1 & 0.1 & tr. & 0.1 & 0.1 & 0.1 & 0.1 & 0.2 & 0.1 & NS & $<0.05$ & NS \\
\hline $20: 3 n-6$ & 2.9 & $3.1 \mathrm{c}$ & 2.1 & $2.5 \mathrm{~b}$ & 2.1 & $2.7 \mathrm{~b}$ & 1.0 & $1.0 \mathrm{a}$ & 0.2 & $<0.01$ & $<0.01$ & NS \\
\hline $20: 4 n-6$ & 8.6 & $7.8 \mathrm{~b}$ & 16.9 & $14.8 \mathrm{~d}$ & 5.2 & $4.3 \mathrm{a}$ & 11.5 & $7.0 \mathrm{c}$ & 1.0 & $<0.01$ & $<0.01$ & $<0.01$ \\
\hline $20: 5 n-3$ & 1.3 & $0.6 \mathrm{~b}$ & 0.2 & tr. a & 5.1 & $3.6 \mathrm{~d}$ & 3.5 & $3.2 \mathrm{c}$ & 0.8 & $<0.01$ & $<0.05$ & NS \\
\hline $22: 5 n-3$ & 0.2 & $0.3 \mathrm{~b}$ & 0.1 & tr. a & 0.7 & $0.7 \mathrm{c}$ & 0.6 & $0.8 \mathrm{c}$ & 0.1 & $<0.01$ & NS & NS \\
\hline $22: 6 n-3$ & 11.3 & $9.4 \mathrm{~b}$ & 8.7 & $6.5 \mathrm{a}$ & 7.6 & $7.9 \mathrm{a}$ & 20.0 & $18.4 \mathrm{c}$ & 1.2 & $<0.01$ & $<0.01$ & NS \\
\hline PI & 159 & $134 \mathrm{a}$ & 165 & $140 \mathrm{a}$ & 148 & $137 \mathrm{a}$ & 243 & $214 b$ & 31 & $<0.01$ & $<0.01$ & NS \\
\hline $\begin{array}{l}\text { Total fatty acids } \\
\text { (mg/g liver) }\end{array}$ & 10.57 & 9.53 & 11.63 & 9.76 & 10.64 & 9.50 & 11.34 & 9.40 & 0.50 & NS & $<0.05$ & NS \\
\hline
\end{tabular}

Mice were fed the BT, SO, PO or FO diets for 10 weeks and treated with vehicle or $\mathrm{CCl}_{4}$ twice a week from the third week to the tenth week. Samples were taken $3 \mathrm{~d}$ following the last injection. Lipids were extracted from the liver with chloroform-methanol, and PC was separated by thin-layer chromatography on a silica gel and quantified by gas-liquid chromatography. Values are means from 4 mice. Values with different letters are significantly different $(p<0.05)$ by means comparisons among the dietary groups. a Pooled S.D. $=(\text { Error sum of squares/degree of freedom })^{1 / 2}$. Abbreviations used are: N.D., not detected; NS, not significant; tr., trace; PI, Peroxidizability Index.

Table 4. Fatty Acid Composition of Liver PE in Mice Fed the Experimental Diets

\begin{tabular}{|c|c|c|c|c|c|c|c|c|c|c|c|c|}
\hline \multirow{3}{*}{ Fatty Acid } & \multicolumn{12}{|c|}{$\%$ of Total fatty acid } \\
\hline & \multicolumn{2}{|c|}{ BT } & \multicolumn{2}{|c|}{ SO } & \multicolumn{2}{|c|}{$\mathrm{PO}$} & \multicolumn{2}{|c|}{ FO } & \multirow{2}{*}{$\begin{array}{l}\text { Pooled } \\
\text { S.D. }{ }^{a)}\end{array}$} & \multicolumn{3}{|c|}{ ANOVA } \\
\hline & Control & $\mathrm{CCl}_{4}$ & Control & $\mathrm{CCl}_{4}$ & Control & $\mathrm{CCl}_{4}$ & Control & $\mathrm{CCl}_{4}$ & & Diet & $\mathrm{CCl}_{4}$ & $\operatorname{Diet} \times \mathrm{CCl}_{4}$ \\
\hline $16: 0$ & 18.1 & $17.4 \mathrm{~b}$ & 16.9 & $14.4 \mathrm{a}$ & 15.3 & $15.3 \mathrm{a}$ & 19.7 & $19.0 \mathrm{~b}$ & 1.6 & $<0.01$ & NS & NS \\
\hline $16: 1$ & 0.7 & 1.1 & 0.8 & 0.6 & 0.9 & 0.8 & 1.0 & 0.9 & 0.6 & NS & NS & NS \\
\hline $18: 0$ & 20.7 & $21.2 \mathrm{a}$ & 21.2 & $26.0 \mathrm{~b}$ & 24.0 & $28.1 \mathrm{c}$ & 24.6 & $23.7 \mathrm{bc}$ & 2.1 & $<0.01$ & $<0.05$ & $<0.05$ \\
\hline $18: 1$ & 10.4 & $11.6 \mathrm{c}$ & 9.7 & $6.5 \mathrm{~b}$ & 10.1 & $8.2 \mathrm{~b}$ & 5.1 & $4.9 \mathrm{a}$ & 1.3 & $<0.01$ & $<0.01$ & $<0.05$ \\
\hline $18: 2 n-6$ & 5.3 & $5.2 \mathrm{~b}$ & 7.3 & $6.5 c$ & 8.4 & $6.9 \mathrm{~d}$ & 2.5 & $2.3 \mathrm{a}$ & 0.7 & $<0.01$ & $<0.01$ & NS \\
\hline $18: 3 n-3$ & 0.2 & $0.4 \mathrm{a}$ & tr. & $0.4 \mathrm{a}$ & 1.7 & $1.4 \mathrm{~b}$ & 0.3 & $0.9 \mathrm{a}$ & 0.4 & $<0.01$ & NS & NS \\
\hline $20: 0$ & 0.3 & 0.5 & 0.3 & 0.3 & 0.3 & 0.3 & 0.1 & 0.3 & 0.1 & $<0.01$ & $<0.01$ & NS \\
\hline $20: 1$ & 0.2 & 0.2 & 0.2 & 0.1 & 0.2 & 0.3 & 0.1 & 0.2 & 0.1 & NS & NS & NS \\
\hline $20: 3 n-6$ & 1.1 & $1.3 \mathrm{~b}$ & 1.0 & $1.2 \mathrm{~b}$ & 0.9 & $1.4 \mathrm{~b}$ & 0.3 & $0.4 \mathrm{a}$ & 0.2 & $<0.01$ & $<0.01$ & NS \\
\hline $20: 4 n-6$ & 15.3 & $14.0 \mathrm{~b}$ & 19.9 & $18.5 \mathrm{c}$ & 9.9 & $6.9 \mathrm{a}$ & 9.3 & $5.3 \mathrm{a}$ & 1.3 & $<0.01$ & $<0.01$ & NS \\
\hline $20: 5 n-3$ & 1.7 & $1.3 \mathrm{~b}$ & 0.2 & $0.1 \mathrm{a}$ & 7.8 & $5.8 \mathrm{~d}$ & 3.7 & $2.2 \mathrm{c}$ & 0.7 & $<0.01$ & $<0.01$ & $<0.05$ \\
\hline $22: 5 n-6$ & N.D. & $0.1 \mathrm{a}$ & 0.1 & $0.4 \mathrm{~b}$ & N.D. & N.D. a & 0.5 & $0.5 \mathrm{c}$ & 0.1 & $<0.01$ & $<0.01$ & NS \\
\hline $22: 5 n-3$ & 0.5 & $0.6 \mathrm{~b}$ & 0.1 & $0.3 \mathrm{a}$ & 1.4 & $1.9 \mathrm{c}$ & N.D. & $0.7 \mathrm{ab}$ & 0.3 & $<0.01$ & $<0.01$ & NS \\
\hline $22: 6 n-3$ & 23.4 & $23.3 \mathrm{~b}$ & 19.4 & $22.2 \mathrm{a}$ & 18.1 & $21.5 \mathrm{a}$ & 31.2 & $36.9 \mathrm{c}$ & 2.1 & $<0.01$ & $<0.01$ & NS \\
\hline PI & 271 & $264 \mathrm{a}$ & 249 & $270 \mathrm{a}$ & 254 & $259 \mathrm{a}$ & 313 & $342 b$ & 18 & $<0.01$ & NS & NS \\
\hline $\begin{array}{l}\text { Total fatty acids } \\
\text { (mg/g liver) }\end{array}$ & 5.15 & 5.03 & 5.43 & 5.22 & 5.32 & 5.33 & 5.33 & 5.13 & 0.51 & NS & NS & NS \\
\hline
\end{tabular}

Mice were fed the BT, SO, PO or FO diets for 10 weeks and treated with the vehicle or $\mathrm{CCl}_{4}$ twice a week from the third week to the tenth week. Samples were taken $3 \mathrm{~d}$ following the last injection. Lipids were extracted from the liver with chloroform-methanol, and PE was separated by thin-layer chromatography on a silica gel and quantified by gasliquid chromatography. Values are means from 4 mice. Values with different letters are significantly different $(p<0.05)$ by means comparisons among the dietary groups. a) Pooled S.D. $=(\text { Error sum of squares/degree of freedom })^{1 / 2}$. Abbreviations used are: N.D., not detected; NS, not significant; tr., trace; PI, Peroxidizability Index.

\section{DISCUSSION}

Previously, we demonstrated that liver injury in mice following a single $\mathrm{CCl}_{4}$ treatment was not enhanced in the $\mathrm{FO}$ group compared with the BT group. ${ }^{15)}$ Similarly, we demonstrated in the present study that the $\mathrm{FO}$ diet did not enhance the vulnerability of liver to chronic $\mathrm{CCl}_{4}$ treatment compared with the diets containing less autoxidizable fatty acids. In contrast, Szende et al. reported that chronic $\mathrm{CCl}_{4}$-induced liver injury (a morphometrically determined ratio of connective tissue) in rats was less pronounced when olive oil was used as a vehicle of $\mathrm{CCl}_{4}$ oral administration compared with sunflower, corn or fish oil. ${ }^{25)}$ In this case, however, fish oil did not enhance liver injury compared with sunflower and corn oil. Unfortunately, the tocopherol content of these oils was not described in this paper; the administration of tocopherol has been reported to suppress chronic liver injury induced by $\mathrm{CCl}_{4}{ }^{26)}$ and minor components in olive oil ${ }^{27)}$ may 
have affected the absorption and/or actions of orally administered $\mathrm{CCl}_{4}$.

For the assessment of tissue lipid peroxide, TBARS values have been used extensively, ${ }^{19}$ ) but the values measured in the presence and absence of an antioxidant differed significantly. ${ }^{15)}$ Using a HPLC-chemiluminescence method, different results have been reported for the tissue lipid peroxide levels in rats fed fish oil or safflower oil. ${ }^{28,29)}$ Although we determined TBARS values measured in the presence of an antioxidant (Fig. 2), we cannot completely exclude the possibility that these values still include artificial values associated with sample handling and reaction conditions.

Protein carbonyls are generated by the direct oxidation of proteins or by the introduction of carbonyl moieties into proteins from peroxidative degradation products of PUFA ${ }^{24,30)}$; therefore they may be a good measure of free radical-mediated lipid peroxidation in vivo. Galelli et al. reported that liver microsomes from $\mathrm{CCl}_{4}$-poisoned animals exhibit significantly increased protein carbonyl levels at 1 and $2 \mathrm{~h}$ after administration but not at $3 \mathrm{~h},{ }^{31)}$ indicating that protein carbonyls generated by $\mathrm{CCl}_{4}$ treatment are cleared rapidly. In contrast, we found that the protein carbonyl content in liver was similar among the groups of mice placed on diets containing fatty acids with varying autoxidizablities, and was not elevated but decreased following chronic treatment with $\mathrm{CCl}_{4}$ (Fig. 3).

The fact that feeding highly autoxidizable PUFA decreases the concentrations of tissue $\alpha$-tocopherol in humans ${ }^{8)}$ and animals $^{11)}$ has been interpreted to reflect the consequence of oxidative consumption of $\alpha$-tocopherol. However, chronic $\mathrm{CCl}_{4}$ treatment significantly increased liver $\alpha$-tocopherol levels in mice given the BT diet but not so significantly in the other dietary groups (Fig. 4). $\mathrm{CCl}_{4}$ is known to inhibit lipoprotein secretion from hepatocytes and to induce fatty liver. ${ }^{32)}$ In our present study, TG level was positively correlated with the $\alpha$-tocopherol level in liver (liver TG contents vs. liver $\alpha$-tocopherol contents, $r=0.529, p<0.01, n=40)$. Consistent with this observation, Nagita and Ando previously showed that the hepatic $\alpha$-tocopherol content was positively correlated with hepatic triacylglycerol in adult patients with liver disease. ${ }^{33)}$ We concluded that $\alpha$-tocopherol status is not an indirect index for lipid peroxidation in the body but is regulated largely by the lipid levels in tissues.

A decrease in AA content in liver phospholipids following chronic $\mathrm{CCl}_{4}$ treatment (Tables 3 and 4) was a phenomenon similar to that which occurred following single time $\mathrm{CCl}_{4}$ treatment, ${ }^{15)}$ suggesting an enhanced generation of arachidonate-derived metabolites. The beneficial effects of several eicosanoid synthesis inhibitors and eicosanoid antagonists on liver injury induced by chronic $\mathrm{CCl}_{4}$ treatment in mice have been reported, ${ }^{34)}$ although n-3 fatty acids did not suppress liver injury estimated as ALT activities and hydroxyproline (Fig. 1). DHA is more susceptible to autoxidation than AA in the atmosphere. Although the DHA in the PC content decreased significantly following $\mathrm{CCl}_{4}$ treatment (Table 3 ), it could be due to an impaired PE methyltransferase system which formed the PC or impaired the de novo phospholipid synthetic system ${ }^{35,36)}$; DHA containing species of $\mathrm{PC}$ is known to be synthesized exclusively from PE by this pathway. ${ }^{37)}$ In fact, the DHA content in PE increased (Table 4).

A number of studies have demonstrated that fish oil diets under endogenous antioxidant deficiency lead to an accumu- lation of lipid peroxide products in vivo, which, however, can be almost totally restored by tocopherol supplementation. ${ }^{38)}$ Under antioxidant deficiency, $\mathrm{CCl}_{4}$ injection increased both lipid peroxidation, as measured by ethane evolution, and mortality in rats fed cod liver oil compared with those fed lard. ${ }^{39)}$ However, $\mathrm{CCl}_{4}$-induced liver injury was reported to be suppressed by sufficient tocopherol supplementation. ${ }^{40)}$ Taking these and our present results together, we conclude that feeding highly autoxidizable n-3 PUFA does not accelerate the development of oxidative stress-induced liver injury induced by $\mathrm{CCl}_{4}$ when sufficient amounts of antioxidants are present. In contrast, many lines of evidence indicate that long-term feeding using oils enriched with n-3 PUFA suppresses the development of so-called free radical diseases: aging, carcinogenesis and atherosclerosis, by suppressing ischemia/inflammation, as summarized elsewhere. ${ }^{41)}$

Acknowledgments We are indebted to Akiko Takagi for her excellent technical assistance. This work was supported in part by Special Coordination Funds for Promoting Science and Technology from the Science and Technology Agency of the Japanese Government, by a Grant-in-Aid for Scientific Research from the Ministry of Education, Science, Sports and Culture of Japan, and by Suzuken Memorial Foundation.

\section{REFERENCE}

1) Brattin W. J., Glende E. A. J., Recknagel R. O., J. Free Rad. Biol. Med., 1, 27-38 (1985).

2) Poli G., Albano E., Dianzani M. U., Chem. Phys. Lipids, 45, 117-142 (1987).

3) Harman D., J. Gerontol., 11, 298-300 (1956).

4) Harman D., J. Gerontol., 23, 476-482 (1968).

5) Harman D., Age , 7, 111-131 (1984).

6) Harman D., Hendricks S., Eddy D. E., Seibold J., J. Am. Geriatr. Soc., 24, 301-307 (1976).

7) Yagi K., Chem. Phys. Lipids, 45, 337-351 (1987).

8) Meydani M., Nantiello F., Golden B., Free N., Woods M., Schaefer E., Blumberg J. B., Gorbach S. L., J. Nutr., 121, 484-491 (1991).

9) Kaasgaard S. G., Hølmer G., Høy C.-E., Behrens W. A., Beare-Rogers J. L., Lipids, 27, 740-745 (1992).

10) Meydani S. N., Shapiro A. C., Meydani M., Macauley J. B., Blumberg J. B., Lipids, 22, 345-350 (1987).

11) Cho S.-H., Choi Y.-S., Lipids, 29, 47-52 (1994).

12) Javouhey-Donzel A., Guenot L., Maupoli V., Rochette L., Rocquelin G., Lipids, 27, 651-655 (1993).

13) Kromhout D., Bosschieter E. B., de Lezenne Coulander C., N. Engl. J. Med., 312, 1205-1209 (1985).

14) Simopoulos A. P., Am. J. Clin. Nutr., 54, 438-463 (1991).

15) Yasuda S. Watanabe S., Kobayashi T., Okuyama H., Lipids, 32, 1249-1255 (1997).

16) Witting L. A., Horwit M. K., J. Nutr., 82, 19-25 (1964).

17) Hörder M., Rei R., "Methods of Enzymatic Analysis," Vol. 3, ed. by Bergmeyer H. U., Verlag Chemie, Weinheim, 1984, pp. 444- 456.

18) Wossner J. F. J., Arch. Biochem. Biophys., 93, 440-447 (1961).

19) Kikugawa K., Kojima T., Yamaki S., Kosugi H., Anal. Biochem., 202, $249-255$ (1992).

20) Nakamura A., Goto S., J. Biochem. (Tokyo), 119, 768-774 (1996).

21) Bligh E. G., Dyer W. J., Can. J. Biochem. Physiol., 37, 911-917 (1959).

22) Abe K. Ohmae M., Katsui G., Vitamins (Japan), 50, $453-457$ (1976).

23) Martines-Hernandez A., Lab. Invest., 53, 225-234 (1985).

24) Dean R. T., Fu S., Stocker R., Davies M. J., Biochem. J., 324, 1-18 (1997).

25) Szende B., Timár F., Hargitai B., Exp. Toxic. Pathol., 46, 355-359 (1994).

26) Parola M., Leonarduzzi G., Biasi F., Albano E., Biocca M. E., Poli G., Dianzani M. U., Hepatology, 16, 1014-1021 (1992). 
27) Huang M.-Z., Watanabe S., Kobayashi T., Nagatsu A., Sakakibara J., Okuyama H., Lipids, 32, 745-751 (1997).

28) Miyazawa T., Suzuki T., Fujimoto K., Yasuda K., J. Lipid Res., 33, $1051-1058(1992)$

29) Ando K., Nagata K., Beppu M., Kikugawa K., Kawabata T., Hasegawa K., Suzuki M., Lipids, 33, 505-512 (1998).

30) Esterbauer H., Schaur R. J., Zollner H., Free Radical Biol. Med., 11, $81-128$ (1991).

31) Galelli M. E., Gómez M. I. D., Castro G. D., Castro J. A., Redox Report, 3, 23-29 (1997).

32) Pencil S. D., Brattin E. A., Glender E. A. J., Recknagel R. O., Biochem. Pharmacol., 33, 2419-2423 (1984).

33) Nagita A., Ando M., Hepatology, 26, 392-397 (1997).

34) Shimazawa T., Nagai H., Koda A., Kasahara M., Prostag. Leukotr. Es- sent. Fatty Acids, 40, 67-71 (1990).

35) Halbreich A., Mager J., Biochim. Biophys. Acta, 187, 584-587 (1969).

36) Shimizu Y., J. Lipid Res., 10, 479-486 (1969)

37) Hill E. E., Husbands D. R., Lands W. E., J. Biol. Chem., 243, 44404451 (1968).

38) Ibrahim W., Lee U.-S., Yeh C.-C., Szabo J., Bruckner G., Chow C. K., J. Nutr., 127, 1401-1406 (1997).

39) Hafeman D. G., Hoekstra W. G., J. Nutr., 107, 656-665 (1977).

40) Yoshikawa T., Furukawa Y., Murakami M., Takemura S., Kondo M., Digestion, 25, 222--229 (1982).

41) Okuyama H., Kobayashi T., Watanabe S., Prog. Lipid Res. 35, 409 457 (1997). 